\title{
EL PROCESO DE INCORPORACIÓN POLÍTICA. DE LOS SECTORES INDÍGENAS EN EL ECUADOR. PACHAKUTIK, UN CASO DE ESTUDIO
}

\author{
Francisco Sánchez López* y Flavia Freidenberg **
}

\section{INTRODUCCIÓN}

En la historia política de Ecuador los indígenas han sido tradicionalmente excluidos del proceso de toma de decisiones. A pesar de que «lo indio» constituyera un elemento fundacional de la sociedad ecuatoriana, el sistema político ha marginado su integración y participación en la política del país. Desde 1830, en los albores de la vida republicana, ya se hablaba de una República de blancos y de una República de indios. A través de los años, esta idea fue dando forma a la política ecuatoriana ya que los indígenas han sido excluidos a partir de diferentes mecanismos entre los que pueden mencionarse el ordenamiento jurídico del Estado y la cultura política de sus habitantes.

En las tres últimas décadas la situación se ha ido transformando. Paralelamente al proceso de democratización, los indígenas han comenzado a organizarse y, desde el levantamiento de $1990^{1}$, se han convertido en un actor con gran capacidad de presión en la vida política del país y con gran influencia en la toma de decisiones. Este trabajo reflexiona acerca del proceso de incorporación política de los indígenas en el marco institucional del Ecuador. La hipótesis principal es que el proceso de modernización rural llevado a cabo desde el Estado, la iglesia, las organizaciones no gubernamentales (ONG's) y los organismos internacionales ${ }^{2}$ ha facilitado la incorporación del sector indígena campesino al sistema político ecuatoriano.

Este problema se sitúa en la intersección de tres espacios de reflexión: la formación del Estado, la ciudadanía y los movimientos sociales. Para su comprensión resulta necesario pensar como los indígenas dejaron de ser un actor social marginal para convertirse en un actor protagonista del sistema político y, además, analizar la coyuntura específica de la década de 1990 que permitió la participación del sector indígena en las instituciones políticas.

En primer lugar, referirse a un proceso de incorporación de fuerzas sociales al sistema político supone muchas veces pensar en un sistema que aún no ha terminado de constituirse, lo que podría considerarse como una comunidad política en proceso de modernización. Esto significa que en algunos países, como el Ecuador, donde el Estado y la nación continúan construyéndose, los clivajes ${ }^{3}$ deben entenderse de manera más dinámica pues existen sectores que no fueron tomados en cuenta como parte del estado o la nación, ya que estaban excluidos a pesar de formar parte de lo social. En el caso de estudio la incorporación del conflicto étnico como parte de la redefinición del Estado y lo nacional ha dado como resultado, por medio de la politización de los conflictos sociales, una alianza entre el clivaje étnico y el ideológico (izquierdaderecha) ${ }^{4}$ que si bien puede pensarse como representativos de una tensión existente en el sistema político desde el momento fundacional, recién se ha manifestado en comportamientos y organizaciones políticas en los últimos años. En este mismo sentido, Bartolini y Mair (1990) sostienen que una división puede pasar mucho tiempo sin manifestarse en la escena política pero eso no significa que la tensión estructural no exista. El matiz analítico se encuentra en que esa tensión latente se traduzca políticamente ya sea en organizaciones (por ejemplo, partidos políticos) o en comportamientos (entre los que podrían ubicarse los modos alternativos de acción política) y pase a ser percibida e incorporada como un conflicto central

Pontificia Universidad Católica del Ecuador

** Instituto de Estudios de Iberoamérica y Portugal, Universidad de Salamanca.

1. En ese levantamiento, los sectores indígenas ocuparon la Iglesia de Santo Domingo en la ciudad de Quito, tomaron algunas ciudades de la sierra y obstruyeron las principales carreteras del país.

2. Siguiendo a Escobar (1993), denominaremos a ese conjunto de instituciones como "aparato del Desarrollo".

3. Un cleavage (castellanizado como clivaje) puede ser traducido como una coyuntura histórica crítica o como línea de conflicto, de fractura o de tensión. Estos pueden ser entendidos como una ruptura social y, desde esta postura, como un elemento estructural más estático que dinámico. En tanto, la alianza de clivajes es de naturaleza dinámica aunque no siempre se traduzca políticamente.

4. El trabajo seminal sobre los cleavage es el de Lipset y Rokkan (1992) que, a partir del esquema clásico de Talcott Parsons para la clasificación de funciones de un sistema social, analizan las bases de división posibles dentro de comunidades políticas nacionales y los alineamientos de los votantes. Los autores señalan la existencia de un cruce de dimensiones a partir de dos ejes, que da como resultado una configuración de cuatro conflictos básicos: oposiciones dentro de la élite nacional estable cida frente a oposiciones locales-regionales; oposiciones de intereses concretos frente a oposiciones ideológicas (241: Fig 10.2). En Europa una alianza clásica ha sido la que se dio entre el clivaje de oposiciones ideológicas con las oposiciones locales regionales. 
en la sociedad y el sistema político. Esta noción dinámicas permite analizar sistemas en donde hay sectores que no están incluidos o que se incorporan en momentos posteriores a su configuración fundacional (el Partido Verde Alemán o el caso de estudio).

En segundo lugar, uno de los fenómenos que genera la modernización es precisamente la incorporación de esos grupos que no se encuentran incluidos en el sistema político. Huntington (1997:349) sostiene que es la modernización la que «...crea y conlleva a la conciencia y actividad política a grupos sociales o económicos (...) que se encontraban fuera de la esfera... política...» En un momento determinado los miembros de esas fuerzas sociales toman conciencia de su situación y tras siglos de exclusión, como en el caso ecuatoriano, comienzan a presionar para participar en el sistema. En este escenario cabe hacer dos precisiones: a) la incorporación de nuevos grupos sociales puede conducir a una modificación en la distribución del poder en el sistema político, eso es, una nueva correlación de fuerzas y b) la incorporación de un nuevo grupo no significa necesariamente que ese grupo se sienta identificado con el sistema político. Esta diferencia de matices es muy importante dado que formar parte no significa sentirse parte.

La cuestión indígena como exclusión puede ser analizada desde dos niveles: el estatal y el societal. En cuanto al primer nivel de análisis cabe mencionar que una de las funciones que tradicionalmente correspondieron al modelo de Estado nacional republicano ha sido la de construir ciudadanías. Este principio de la ciudadanía ha implicado desde su génesis una universalidad: la de otorgar igualdad de derechos a todos los individuos. Como señala Alcántara (1997:62), "... el estado es el marco donde los individuos se hacen ciudadanos...". Para convertirse en ese espacio, el Estado debe disponer de "... reglas de juego para todos, en las que todos quepan...". A pesar de ello, el Estado ecuatoriano ha colaborado en la reproducción de las diferencias sociales y económicas, lo que ha acentuado aún más la exclusión de los sectores indígenas al proceso político".

Desde la época colonial se ha desarrollado una legislación especial para los indios. Hasta 1857, mediante la figura del Tributo de Indios, el Estado aparecía como el protector de las comunidades indígenas pero al mismo tiempo se erigía en el elemento de exclusión de este sector (la muestra de ello se encuentra en un elemento básico: la existencia de ese Tributo). Años más tarde, el Estado se desentendió de todo lo relacionado con lo indígena al eliminarlos del registro público (Guerrero, 1997:64). Desde ese momento no se registraron más los nacimientos ni las defunciones de las comunidades. Así, de la protección paternalista del Estado se pasa a la supresión de la existencia pública de los indígenas, a partir de la "privatización" del control de las comunidades, convirtiéndose el Estado en un mero intermediario que se ha limitado a traducir al español lo relacionado con "lo indio".

En el caso de Ecuador, podría indicarse la existencia de una legislación para todos los ciudadanos y otra especial para las comunidades ${ }^{7}$, donde históricamente se han dado dos tipos de ciudadanos y dos tipos de leyes, lo que ha convertido al Estado en el primer elemento diferenciador y de exclusión de este grupo social. Como señala Guerrero (1997:64), esto es una “... paradoja... puesto que en el discurso mismo de la ciudadanía no puede haber este tipo de clasificatorios, dado su carácter universal..." En estos términos, el Estado ecuatoriano ha sido el que marcó la primera diferencia: las diferencias en la ciudadanía.

Desde el segundo nivel de análisis, el societal, se puede abordar la cuestión desde una perspectiva más vinculada al problema de la identidad. La constitución de la sociedad ecuatoriana está atravesada por una diferencia identitaria básica, caracterizada según Ibarra (1992) por “... la oposición histórica entre lo blanco-occidental y lo indígena, (que) se presenta como un conflicto cultural de larga duración, cuyo desafío presente es la vigencia del racismo y la crisis de los modelos y propuestas de integración social..." En una posición más extrema, hay autores como Pachano (1996) que señalan que la sociedad ecuatoriana no se ha constituido como tal y que en realidad aún existen grupos que no se reconocen como partes constitutivas de un todo societal, la diferencia que señalábamos anteriormente entre formar parte y sentirse parte, en este caso, de la sociedad.

En ese escenario el tema del racismo aparece como el instrumento más eficaz para señalar las diferencias. Según Almeida (1992) en la sociedad ecuatoriana «... prevalecen mecanismos de sobre-explotación a (los) indígenas... (así) no debe extrañar que quienes usufructúan hasta ahora de esa situación de explotación se vean en la necesidad de confrontar las impugnaciones de esta población haciendo uso del arma más eficaz, después de la represión física; es decir; la ideológica. En cierta medida, solamente con la activación de este poderoso recurso es que (se mantienen los)... procesos de dominación sociocultural...". En la misma línea, Guerrero (1998) describe la existencia de "matrices de clasificación binaria" que funcionan como elementos de significación de diferencias en términos de dominación y que suponen en sí mismas relaciones de inferioridad. Muchas veces es como sí ellos mismos, por el sólo hecho de ser indígenas, se ubicaran por debajo de los otros. En estas matrices que describe Guerrero aparece una relación de dominación autoexcluyente donde lo blanco-mestizo es la dominación y lo indígena aparece como lo dominado. Para que se de la existencia de una, necesariamente se debe dar la otra. Juntas dan sentido a lo que podríamos denominar

5. En este caso resulta más útil el concepto de clivaje propuesto por Ronald Inglehart, que se refiere a patrones estables de polarización del conflicto. Según este autor un clivaje puede ser definido como: “... relatively stable patterns of polarization in which given groups support given policies or parties, while other gropus support opposing policies or parties. For almost a generation, the nature of (1) the groups and (2) the policy issues aligned with Left and Right have been changing...” (1984: 24).

6. En 1986, el dirigente indígena Alberto Andrango (1986:247) señalaba que en Ecuador «... las comunidades viven aisladas del funcionamiento del Estado, porque éste no cumple su función [...] en igualdad de condiciones para todos [...] Solamente funciona para [...] los sectores urbanos, pero para las comunidades casi no se ha hecho [...] nada y de ahí que en las comunidades exista un desconocimiento de lo que es el Estado...».

7. Para una visión histórico-jurídica del problema del indio en el Ecuador se puede ver Donoso (1992) o Ayala Mora y otros (1992) que plantean el problema jurídico de la relación entre los indios y el Estado desde una perspectiva más actual. 
como una cultura política con prejuicios raciales, considerando que por definición la cultura política está vinculada con los imaginarios sociales.

\section{ETAPAS EN EL PROCESO DE INCORPORACIÓN DE LOS SECTORES INDÍGENAS AL MARCO INS- TITUCIONAL}

La incorporación del sector indígena al marco político institucional ecuatoriano es un fenómeno reciente. Históricamente, las demandas étnicas no contaban con una fuerte articulación ni se expresaban en organizaciones políticas, debates públicos o Asambleas Constituyentes donde los principales protagonistas fueran los propios indígenas, con sus organizaciones y sus dirigentes. En las tres últimas décadas se ha dado un proceso novedoso que ha transformado siglos de historia. Este fenómeno, que no es exclusivo del Ecuador sino que se ha dado con características particulares en otros países de América Latina como México, Bolivia y Guatemala, ha coincidido con los procesos de transición a la democracia de esos sistemas políticos. Con fines explicativos, la incorporación del sector indígena en el Ecuador puede ser presentada en tres etapas: a) etapa simbólica de incorporación generada desde el Estado (promoción de la incorporación desde "dentro"); b) etapa de movilización de los sectores indígenas (movilización desde «fuera») y c) etapa de integración institucional al sistema político (promoción de la incorporación mixta: desde dentro y desde fuera).

\section{a) Etapa simbólica de incorporación generada desde el Estado (promoción de la incorporación desde "dentro")}

El desarrollo rural de los últimos cincuenta años en el Ecuador puede describirse a través de una serie de modelos que muestran las diferentes políticas estatales y de desarrollo privado e internacional hacia el sector indígena campesino. A partir de una clasificación básica realizada por Sylva (1990) puede señalarse el siguiente esquema:

1. Desarrollo de la comunidad: En el año 1954, Naciones Unidas promovió el Programa Andino para el Desarrollo de los Grupos Indígenas. Este Programa tenía como objetivo cubrir la falta de conocimiento y comunicación de los agricultores a través del desarrollo de acciones educativas y discusiones entre miembros de la comunidad y los funcionarios del gobierno. La intención de Naciones Unidas era comenzar a estrechar lazos entre los sectores campesinos y el Estado. Los efectos de este Programa fueron limitados, en particular, si se considera las condiciones en las que se daban las relaciones sociales y económicas en el campo. Así, el primer intento de desarrollo rural estuvo coordinado desde una organización internacional.

2. El Desarrollo Rural: este modelo fue aplicado desde el Estado entre 1964 y 1975. El mismo planteaba la modernización del agro con el uso de insumos y técnicas modernas de cultivo. Además, señalaba la necesidad de la redistribución del recurso tierra y de la organización en el campo. En un período de diez años, de la mano de gobiernos militares, la voluntad modernizante del Estado ecuatoriano se puso de manifiesto en dos oportunidades a través de sus intentos de Reforma Agraria.

La primera ley de Reforma Agraria fue dictada por la Junta de Gobierno militar el 11 de julio de 1964. A pesar de las intenciones, la reforma sólo tuvo efectos en especial en las haciendas del Estado y en las de la Iglesia. Al decir de un autor marxista como Cueva (1991) “...la Junta Militar planteó el problema de la reforma agraria y hasta llegó a dictar una ley con ese nombre, que ... fue: una farsa destinada a engañar al campesino y proteger (a la larga) los intereses de los latifundistas..." (237).

La segunda ley de Reforma Agraria, dictada en 1973 por la dictadura de Guillermo Rodríguez Lara, tuvo mejores resultados si los comparamos con la primera. Más allá de los cambios legales introducidos posteriormente, esta ley posibilitó un cambio real en las relaciones socio-económicas del sector rural aunque no supuso una total transformación en la tenencia de la tierra. La diferencia sustancial entre los dos intentos de Reforma fue que la segunda estuvo acompañada por la implementación de "Proyectos de Desarrollo" que involucraban tanto al Estado como a organizaciones no gubernamentales, iglesias y organismos internacionales. Los mismos estaban integrados por una serie de componentes que trataban las más variadas materias como la realización de módulos socio-organizativos, de capacitación y educación, de producción y de infraestructura.

3.- Desarrollo Rural Integral (DRI): este modelo se planteó entre 1978 y 1984. Las estrategias en esta oportunidad eran la participación social, la autogestión y la organización campesina. El Estado y las instituciones privadas pretendían impulsar la mejora de las condiciones de producción y de vida de los campesinos, entendiendo el problema del desarrollo como un problema integral y pretendiendo atender todas las esferas de la vida rural. Dentro de esta lógica de desarrollo se diseñaron planes más amplios de desarrollo rural como los implementados por el Estado: el Fondo de Desarrollo Rural Marginal (FODERUMA), la Secretaría de Desarrollo Rural Integral (SEDRI), Programas DRI, y actualmente, en vista de sus prácticas, el actual Programa de Desarrollo Rural (PRONADER).

4.- Desarrollo rural "alternativo": en vista de las consecuencias de la «revolución verde» se plantea la necesidad de proponer tecnologías apropiadas para las zonas de intervención, en función de la fragilidad de los ecosistemas de producción. Esta visión del desarrollo en el campo propone rescatar las tecnologías productivas tradicionales pero, siempre y cuando, sean funcionales al mercado. En este modelo de desarrollo se unen tres ideas básicas: a) el respeto a las tradiciones y costumbres de las comunidades indígenas, b) la inserción "real" al sistema productivo a partir del desarrollo de las tecnologías básicas utilizadas por los grupos étni$\cos$ y c) la protección del medio ambiente.

5.- Desarrollo Humano: últimamente se está construyendo un nuevo modelo de desarrollo, partiendo del agotamiento de los esquemas anteriores y considerando los límites que impone el medio ambiente.

Las distintas etapas de la evolución de las políticas de desarrollo no anulan las propuestas anteriores sino que funcionan como una idea ecléctica de cómo practicar el 
desarrollo. Es más, en todos los esquemas se ha fomentando la organización de los actores rurales, manteniéndose esta idea como una de las principales preocupaciones de la intervención de los proyectos de desarrollo.

El proceso modernizador impulsado desde el aparato del Desarrollo ha tenido una serie de consecuencias al interior del sector indígena campesino y en la relación de éste con el Estado y la sociedad. Así, tras la aplicación de algunas de esas políticas de desarrollo es posible identificar una serie de transformaciones de carácter integrador de los indígenas al sistema social y, como se verá posteriormente, estos cambios serán elementos fundamentales en la integración de los indígenas al sistema político. De manera un tanto arbitraria, y sólo con un objetivo descriptivo, esas consecuencias podrían agregarse en dos: un primer grupo que nuclea los cambios que se produjeron en la organización y actuación de las comunidades y un segundo grupo que agrega las transformaciones que modificaron las relaciones de éstas con su entorno.

Las transformaciones fueron las siguientes:

- En la organización y movilización de las comunidades:

a. Estructuración del sector y canalización de sus demandas a través de organizaciones.

b. Formación de una élite gracias a los programas de capacitación.

c. Acceso al uso de la tierra.

d. Primera etapa de "ciudadanización" del sector indígena.

- En las relaciones de las comunidades con su entorno:

a. Transformación de la imagen que los indígenas tenían del Estado.

b. Primeros intentos de incorporación de los indígenas a la institucionalidad por parte de las élites políticas y del Estado.

- En la organización y movilización de las comunidades: a. Estructuración del sector y canalización de sus demandas a través de organizaciones. El requisito legal, impuesto por el Estado, para la entrega de las tierras a las comunidades fue el de la organización. Así, el ente estatal estableció que no se darían tierras a personas particulares sino que sólo se haría a entes organizados. Este requisito condujo a un fenómeno específico que fue el de la agregación de intereses de los sectores indígenas. En el Cuadro I es posible observar, como ejemplo, el crecimiento de las organizaciones en el sector rural en los distintos períodos en la provincia de Chimborazo, la de mayor población indígena del país ${ }^{8}$. En este sentido, se observa que desde mediados de la década del sesenta se han creado en esa provincia 662 organizaciones, entre las que prevalecen las de tipo comunal (494). Si analizamos más detalladamente los datos de ese cuadro podemos señalar que en un primer período los indígenas privilegiaron el tipo de organización comunal mientras que en el último período analizado (85-91) se ha incrementado el número de asociaciones (cerca de 57) casi igualando al de organizaciones comunales creadas en este último período (58). Esos entes que surgieron en primera instancia por razones legales, para satisfacer una cuestión económica y social, fueron los que sentaron las bases fundamentales para el posterior surgimiento de las organizaciones políticas, siendo éstas instrumentos decisivos para la movilización política. Así, este requisito legal de organización se mostraría fundamental para el paso hacia la movilización política posterior, lo que en términos de Bartolini y Mair (1990) sería la manifestación de la tensión social en organizaciones y comportamientos políticos

CUADROI I

\begin{tabular}{|c|c|c|c|c|c|c|c|c|}
\hline \multicolumn{9}{|c|}{$\begin{array}{l}\text { Organizaciones campesinas de basc juridicamente reconocidas por tipo de organización seguin fecha de } \\
\text { creación en la provincia de Chimborazo }\end{array}$} \\
\hline \multirow[b]{2}{*}{ Tipo de Organización } & \multirow[b]{2}{*}{64} & \multirow[b]{2}{*}{$65-69$} & \multirow[b]{2}{*}{$70-74$} & \multirow[b]{2}{*}{ 75-79 } & \multirow[b]{2}{*}{$80-84$} & \multirow[b]{2}{*}{$85-91$} & \multicolumn{2}{|c|}{ Total } \\
\hline & & & & & & & $\mathrm{N}^{0}$ & $\%$ \\
\hline Comunas & 186 & 71 & 63 & 38 & 78 & 58 & $49+$ & 74.6 \\
\hline \begin{tabular}{|l} 
Cooperativas \\
\end{tabular} & 7 & 20 & 38 & 8 & 5 & 2 & 80 & 12.1 \\
\hline Asociaciones & -- & - & 1 & 4 & 22 & 57 & $88^{\circ}$ & 13,3 \\
\hline \begin{tabular}{|l|} 
Total \\
\end{tabular} & 193 & 91 & 102 & $50 \mid$ & 105 & 117 & 662 & 100,0 \\
\hline
\end{tabular}

b. Formación de una élite a raíz de los programas de capacitación. Estos programas permitieron la formación de una élite con elevados niveles de educación e información que rápidamente se convirtió en la contraparte del Estado en los procesos de negociación. Esa élite ha sido fundamental en el proceso de incorporación de los sectores indígenas a la vida política ecuatoriana, no sólo por la incorporación en sí sino por el estilo y la manera de hacer política que han empleado.

c. Acceso al uso de la tierra. En el Cuadro II se muestra el acceso diferencial a la tierra que experimentaron los sectores indígenas en los distintos períodos de la Reforma Agraria en la provincia de Chimborazo, siendo el más significativo el del período $75-79$ cuando se adjudicaron unas $67.238 \mathrm{hec}$ táreas solo en dicha provincia.

\begin{tabular}{|c|c|c|c|c|}
\hline \multicolumn{5}{|c|}{$\begin{array}{l}\text { Adjudicaciones realizadas por el Instituto Ecuatorianos de Reforma Agraria y Colonización } \\
\text { (IERAC) en la provincia del Chimborazo }\end{array}$} \\
\hline \multirow[b]{2}{*}{ PERIODOS } & \multicolumn{4}{|c|}{ SUPERFICIE ADJUDICADA } \\
\hline & Has. & $\%$ & $\%$ acumulado & Promedio anual (has) \\
\hline $64-74$ & $20.665,82$ & 18,0 & 18.0 & 1.968 .7 \\
\hline $75-79$ & 67.238 .19 & 55,9 & 73,9 & 13.447 .6 \\
\hline $80-84$ & $20.464,17$ & 17,0 & 90,9 & 4.092 .8 \\
\hline $85-88$ & $8.855,03$ & 7,4 & 98,3 & $2.213,8$ \\
\hline $89-90$ & 2.064 .52 & 1.7 & 100,0 & 1.032 .3 \\
\hline Total & 120.277 .73 & 100,0 & & 4.454 .7 \\
\hline
\end{tabular}

d. Primera etapa de "ciudadanización" del sector indígena, principalmente, a través de las campañas de alfabetiza ción ${ }^{9} y$ de los procesos de documentación. Este último, además de su connotación real, tenía un fuerte sentido simbólico, puesto que el Estado, por medio de los documentos de identidad, otorgaba (y actualmente lo continúa haciendo) certificados de ciudadanía.

- En la relación con el entorno:

a. Transformación de la imagen que los indígenas tenian del Estado. El aparato estatal comenzó a ser vislumbrado

8. La población total del Ecuador para 1997, según el cálculo del Banco Interamericano de Desarrollo (BID), fue de 11.937.000 habitantes. Para 1996, el mismo organismo, calculaba que la población rural com prendía el $38,3 \%$ de la población general.

9. Para 1970 el porcentaje de población analfabeta de 15 y más años de edad era del 25,8\%. Para 1980, del 16,5\% y diez años más tarde alcanzaba el $11,7 \%$. 
como un interlocutor válido donde canalizar las demandas, antes encauzadas a través de relaciones clientelares. A pesar de esa transformación que permitió acercar a las partes del conflicto, actualmente la desconfianza hacia el aparato estatal se mantiene. Una evidencia de esa transformación de visiones está en el reconocimiento mutuo que se da entre Estado y Organizaciones en los procesos de negociación. El hecho de negociar con la otra parte supone la aceptación del otro y la legitimidad del poder que ese pueda tener. Otro dato que muestra que los gobiernos del período analizado han percibido el problema indio de una manera distinta a la tradicional se encuentra en la creación de secretarías de asuntos indígenas en todos los gobiernos (con distintos nombres), lo que alcanzó su mayor expresión en la creación del ministerio indígena en el gobierno de Bucaram (1996-1997)

b. Primeros intentos de incorporación de los indígenas a la institucionalidad por parte de las élites politicas y el Estado. En la nueva etapa democrática, que comenzó en 1979, la élite política otorgó el derecho al voto facultativo a los analfabetos, la mayoría de ellos, indígenas. Así se incluyó en el texto constitucional un artículo que permitía que los analfabetos que quisieran votar pudieran hacerlo (el contenido de ese artículo se ha mantenido en el texto constitucional de 1998). Con esta medida se posibilitó la incorporación política de un amplio sector de la población a una de las instituciones básicas de todo sistema democrático: las elecciones.

De los distintos Planes de Desarrollo, del impulso de la Reforma Agraria de 1973 y de las medidas políticas tomadas por las élites y el aparato estatal se han dado una serie de transformaciones en el ámbito del Estado, la sociedad y el sector indígena. La razón de ese cambio de actitud fue incorporar al sistema político a un sector de la población ${ }^{10}$. Esto es, integrar a los indígenas a las instituciones, a la dinámica política, por ende, a la condición de ciudadanos. Al mismo tiempo, los sectores indígenas fueron modificando paulatinamente la imagen que tenían del Estado. La práctica del desarrollo produjo un cambio en las relaciones económicas y políticas de las zonas rurales, relaciones que habían servido históricamente como mecanismo de sujeción de los indígenas. En este sentido, puede entenderse el desarro1lo, siguiendo la idea de Escobar (1993), como un mecanismo de inclusión tanto al Estado como al mercado de las poblaciones que habían permanecido históricamente al margen de éstos.

\section{b) Etapa de movilización de los sectores indígenas (mo- vilización desde "fuera")}

A finales de la década del ochenta, todas las provincias con población indígena contaban con organizaciones de carácter local, microrregional o provincial como puede observarse en el Cuadro III. Estas organizaciones, además de buscar la satisfacción de las necesidades básicas de sus miembros por medio de la gestión de proyectos de desarrollo ante el Estado y ONG's, dejaban entrever una identidad étnica y actuaban políticamente enfrentadas a los poderes locales y al Estado central (Sánchez-Parga, 1989:247-268). En este marco de impulso organizativo se creó, en junio de 1972 en la comunidad de Tepeyac (Chimborazo), la Confederación de la Nacionalidad y Pueblos Quichuas del Ecuador (ECUARUNARI). Al mismo tiempo, en el Amazonas, se organizó la Confederación de Nacionalidades Indígenas de la Amazonía Ecuatoriana (CONFENAIE).

La ECUARUNARI y la CONFENAIE surgieron en torno a las luchas por la recuperación de las tierras y la defensa de los derechos de los pueblos que representaban, cada una en un ámbito territorial específico. Entre los objetivos generales de ambas y, en particular, de ECUARUNARI se encontraba el de convertirse en referentes de las nacionalidades indígenas en el contexto nacional e internacional. Esas organizaciones étnicas, impulsadas de algún modo por el Estado, se fueron transformando en elementos desafiantes del aparato estatal. Lo que en un primer momento había surgido como una necesidad económica y social, se fue convirtiendo en un instrumento político, en especial, en aquellas comunidades capaces de aprovechar los lazos comunitarios preexistentes. Sólo en las comunidades donde habían existido esos lazos, se han dado las bases para organizar movimientos políticos y para movilizar a las comunidades conectadas por ellos (Yashar, 1998:24). La politización de la identidad indígena ha podido ser expresada en movimientos organizados con mayor facilidad en aquellos espacios donde existían esas vinculaciones anteriores.

CUADRO III

\begin{tabular}{|c|c|c|}
\hline \multicolumn{3}{|c|}{ Organizaciones de segundo grado de la sierra ${ }^{*}$} \\
\hline Provincia & Cantidad de Organizaciones & Año de inicio \\
\hline Azuay & 1 & 1975 \\
\hline Bolívar & 3 & Fines de los años 70 \\
\hline Cañar & 1 & 1974 \\
\hline Carchi & 1 & 1975 \\
\hline Cotopari & 8 & Fines de los años 70 \\
\hline Chimboraz0 & 22 & Fines de los años 60 \\
\hline Imbabura & 12 & Fines de los años 70 \\
\hline Pichincha & 4 & Inicio de los años 60 \\
\hline Tungurahua & 11 & (1) \\
\hline * Nota: no figuran todas las organizaciones de segundo grado pero sí constituyen una muestra representativa. \\
Fuente: Adaptación del Anexo I. Tomado de Sánchez-Parga (1989). Elaboración de los autores.
\end{tabular}

Pero el espacio de lo local y lo regional se fue agotando y los líderes de las organizaciones percibieron la necesidad de disputar reivindicaciones en el ámbito nacional. Por este motivo, estas Confederaciones pasaron en pocos años de la actuación en el ámbito local a actividades de mayor politización a nivel nacional. Si bien existían ya algunas organizaciones nacionales, las mismas que habían sido fundadas a partir de un fuerte vínculo con los partidos de izquierda, esas organizaciones no mantenían estrechas relaciones con las agrupaciones de base. En este escenario, en

10. Diversos argumentos podrían utilizarse para comprender el cambio de actitud de las élites y el Estado hacia los sectores indígenas en las últimas décadas, esto es, las razones que llevaron al Estado y a otras organizaciones a conducir el proceso de modernización social y política. Algunas de ellas podría ser la evaluación de la relación de costos y beneficios de continuar manteniendo excluidos del proceso político a un sector de la población; la percepción de que esos sectores podrían convertirse en una amenaza para el sistema o, quizás, la necesidad de mejorar las condiciones de vida de las comunidades más allá de su integración política. El análisis exhaustivo de esos y otros factores no forman parte central de este estudio pero se consideran relevantes para futuras investigaciones. 
1986, comienza a organizarse la mayor instancia a nivel nacional del movimiento indígena: la Confederación de Nacionalidades Indígenas del Ecuador (CONAIE), tomando como su pilar fundamental a la ECUANUARI y a CONFENAIE. Esa agrupación se convirtió rápidamente en el interlocutor de la representación indígena ante el Estado y el resto de la sociedad a nivel nacional. En la actualidad, la CONAIE congrega a más de 220 organizaciones de todo el país (Voces: 30/11/97). Las ideas políticas e ideológicas de la misma se agrupan en una serie de principios básicos redactados por el Consejo de Gobierno del período 19971999 (Cuadro IV) y contemplados en el Proyecto Político de la CONAIE. Esos principios básicos son el humanismo integral, el comunitarismo, la democracia plurinacional y participativa, la plurinacionalidad, la interculturalidad, la autodeterminación, la soberanía, la independencia y la solidaridad internacional.

CUADRO IV
\begin{tabular}{|l|l|l|}
\hline \multicolumn{1}{|c|}{ CONSEJO DE GOBIERNO - CONAIE. PERIODO 1997-1999 } \\
\hline Presidente & \multicolumn{1}{|c|}{ Nombre } & Comunidad y Proce dencia \\
\hline Vicepresidente & Antonio Vargas & Quichua Pastaza \\
\hline Dir. de Tierras y Territorios & Gonzalo Guzmán & (UOChua Bolivar \\
\hline Dir. de Organización y Formación & Manuel Castro & Quichua Cañar \\
\hline Dir. de Relaciones Internacionales & Angel Gende & Tsa' chila Pichincha \\
\hline Dir. de la Mujer y la Familia & Elvia Dagua & Quichua Pastaza \\
\hline Dir. de Educación e Investigación & Julio Gualán & Quichua Saraguro Loja \\
\hline Dir. de Juventud, Cultura y Deportes & Calixto Añapa & Chachi Esmeraldas \\
\hline Dir. de Salud y Nutrición & Salomón Guiquita & Huaorani Pastaza \\
\hline Fuente: CONAIE. Elaboración de los autores. & \\
\hline
\end{tabular}

La CONAIE tiene su propia interpretación de lo que significa la democracia. Según consta en el Proyecto Político de la Confederación, este sistema político deberá garantizar “...la plena participación de los Pueblos y Nacionalidades en la toma de decisiones y en el ejercicio del poder político... (sustentado) en el respeto a los derechos humanos, a los derechos individuales y colectivos de los Pueblos; en la libertad de pensamiento, en el respeto a las creencias religiosas, en la paz y justicia social... La Democracia Comunitaria del Estado Plurinacional implica un reordenamiento de las estructuras jurídico - políticas, administrativas y económicas que permitan la participación plena de los Pueblos y Nacionalidades indígenas, así como de los otros sectores organizados...". Para la agrupación, la democracia debe ser “... anticolonialista, anticapitalista, antiimperialista, y antisegregacionista, es decir diferente al falso sistema democrático representativo imperante..." (CONAIE, 1997).

El éxito de la CONAIE como organización nacional puede ser atribuido a su carácter étnico en perjuicio de las identidades partidistas y a la vinculación alcanzada con las organizaciones regionales y provinciales que le permitieron un mayor acercamiento a las bases. La CONAIE fue fruto de la unión de las organizaciones indígenas de la Sierra y la Amazonía ${ }^{11}$ con un grupo de dirigentes con altos niveles de educación formal que actuaban políticamente desde el discurso étnico en el ámbito nacional. A pesar de que la Confederación no era una organización muy conocida a fines de la década de $1980^{12}$, llevó adelante un asombroso proceso de consolidación institucional que influyó para que liderara el levantamiento indígena de $1990^{13}$. Según Luis Macas, uno de los líderes del levantamiento, este acontecimiento fue un punto decisivo en el futuro del movimiento indígena.
Quien fuera presidente de la CONAIE señala que con esa acción se consiguió un nuevo espacio político. Su significado puede comprenderse mejor, quizás, utilizando las palabras de este dirigente indígena: “... entramos en la escena política del país [...] por la fuerza de nuestra protesta, tanto la sociedad civil como el Estado se vieron obligados a reconocer a los indios como fuerza política importante [... la cuestión indígena no incumbe solo a los indios, sino que es un problema nacional, que involucra al conjunto de la sociedad ecuatoriana; influir para que las diversas fuerzas sociales y políticas se alineen y tomen posiciones frente a lo indio; reconocer que, a partir del levantamiento, se abre una nueva fase de lucha por la tierra, por reivindicaciones sociales, políticas y culturales del pueblo indio..." (1992:18).

Con esta movilización los sectores indígenas aparecieron con nueva forma en el espacio público. Este hecho fue trascendental ya que rápidamente se convirtió en el debut público de los sectores indígenas organizados, que a partir de allí comenzaron a utilizar de manera organizada «modos alternativos de acción política» (Montero,1995), caracterizados por el actuar espontáneo y la utilización de mecanismos no establecidos por las reglas del sistema político con el objeto de cuestionar de manera abierta y con alta capacidad de movilización al Estado y al sistema político en su conjunto. En este escenario aparece “...una población diferente, que reclama su reconocimiento de la diferencia..." (Guerrero, 1997:63) y lo hace por fuera de las instituciones del sistema político. El corolario del levantamiento fue la negociación directa que se dio entre los miembros del gobierno socialdemócrata de Rodrigo Borja y los dirigentes indígenas acerca de la tenencia de la tierra y algunas reivindicaciones de carácter étnico como la educación bilingüe.

En 1992 se celebraron elecciones generales pero las agrupaciones indígenas no participaron de manera formal y directa en esos comicios, pues se hallaban inmersas en un proceso de "potenciamiento" (empowerment) de sus estructuras y, además, porque su posición seguía siendo muy crítica a los mecanismos del régimen democrático. Las proclamas de estos sectores eran bastante elocuentes: "Queremos acciones, no elecciones", "Esta democracia es una desgracia, por eso queremos nueva democracia", "Sin tierra y sin salud no existe democracia”. De la mano de esa negativa de participar a través de los mecanismos del marco institucional se fue produciendo la aglutinación de distintos sectores indígenas. Esta agregación de intereses fue favorecida por las actividades del

11. La CONFENAIE y el ECUANUARI fueron las dos organizaciones más fuertes que, junto a otras organizaciones menores, dieron sus tento a la CONAIE. En la actualidad, el ECUANUARI agrupa a 13 organizaciones provinciales: diez ubicadas a lo largo del callejón interandino, dos en la amazonía (Morona-Santiago, Zamora-Chinchipe) y uno en la costa ecuatoriana (Esmeraldas).

12. Un sondeo de opinión publicado en abril de 1989 por la CONAIE señalaba que de los 25 dirigentes comunales entrevistados (de) nivel más elemental de la organización de las provincias de Imbabura Cotopaxi y Chimborazo) ninguno conocía a la dirigencia de la CONAIE ni la obra que esta realizaba y sólo tres de ellos sabían que uno de los dirigentes era director de educación indígena del Ministerio de Educación y Cultura (Sánchez-Parga, 1990: 94).

13. Entre la literatura sobre el levantamiento indígena de 1990 cabría destacar Rosero (1990), Moreno (1992) y AA.VV. Indios (1992). 
Quinto Centenario, que condujeron a la formación de un gran movimiento social ${ }^{14}$ reunido bajo la proclama de “ 500 años de Resistencia India, Negra y Popular".

En la naturaleza misma del movimiento se presentaban sus particularidades definitorias: a) un conjunto de creencias y acciones orientadas hacia el cambio social, en este caso, dirigidas al reconocimiento de la plurinacionalidad del Estado, los derechos culturales y étnicos, b) el carácter colectivo de su propuesta, aglutinante de una pluralidad de demandas, c) la estructura interna encargada de elaborar su ideología y dirigir sus acciones, personificada en la CONAIE y en los sectores vinculados a lo que más tarde se llamaría Coordinadora de Movimientos Sociales (CMS), d) el uso de tácticas no convencionales o modos alternativos de acción política y e) la manifestación de conflictividad social, fundamentada en siglos de exclusión social y política desde el Estado y la sociedad ecuatoriana.

El sentido amplio de la proclama presentada permitió que el movimiento integrara otras demandas, lo que influyó para que la naturaleza meramente social del mismo fuera transformándose en política. De este modo, el movimiento indígena se convirtió rápidamente en un actor aglutinante de los sectores populares en un momento en que las organizaciones sindicales estaban desestructuradas y dejaban vacíos de dirección y hegemonía dentro de los sectores de oposición al establishment. Se incorporaron también algunos grupos políticos de izquierda que se encontraban redefiniendo sus posturas ideológicas y políticas a raíz de tres hechos fundamentales: la caída del Muro de Berlín, la derrota de los sandinistas en las elecciones de Nicaragua y las negociaciones del Frente Farabundo Martí para la Liberación Nacional con el gobierno salvadoreño a partir de las cuales la guerrilla aceptaba dejar de ser un elemento antisistema a cambio de una serie de reformas en la institucionalidad del sistema político.

En este escenario se fue configurando un gran frente (que de acuerdo a las coyunturas fue adoptando distintos nombres) en el que la oposición al neoliberalismo y las privatizaciones se convirtieron en el factor de identidad de grupos bastante heterogéneos. El movimiento integraba a los indios, a los sindicatos públicos, a los sectores de izquierda y a grupos minoritarios como el feminista y el ecologista.

En el tercer Congreso de la CONAIE, se resuelve, luego de intensos debates, la participación de las organizaciones en las elecciones municipales. Las razones de los defensores de la participación electoral se centraba en el convencimiento de que el triunfo estaba garantizado en el ámbito local debido a la fortaleza que tenían sus organizaciones en ciertos cantones con población mayoritariamente indígena. De esta manera la Confederación comienza a abandonar de manera paulatina los modos alternativos de acción política y da los primeros pasos hacia la participación política convencional, esto es, la canalización de la participación de las organizaciones por cauces institucionalizados, lo que permitía a la Confederación continuar funcionando sin la necesidad de una movilización y agitación constante ${ }^{15}$. Esta decisión de dar un primer paso desde la "acción política" a la "participación política” comienza a traslucir la toma de conciencia por parte de algunos sectores internos de que los espacios informales de la política en los que se habían movido hasta ese momento se habían agotado y que, para ciertos procesos, necesitaban recurrir a la formalidad que ofrecía la participación en las elecciones. Paralelamente, a través de una reforma constitucional aprobada en Consulta Popular, se permite a partir de 1994 la participación en las elecciones de candidatos no afiliados a partidos políticos ${ }^{16}$, lo cual suponía la apertura de las élites políticas hacia estas organizaciones que siempre se habían mostrado críticas a los partidos políticos y a las instituciones.

El movimiento social que se había formado entorno a los sectores indígenas se fue consolidando, principalmente, por la oposición al proyecto de reforma económica del gobierno de Sixto Durán-Ballén. Al mismo tiempo, ese movimiento se fue instituyendo como actor político relevante por su participación en las movilizaciones y posteriores negociaciones que se dieron en el país a raíz de la aprobación de la Ley de Desarrollo Agrario. Si bien las organizaciones indígenas y campesinas consideraban a esa ley contraria a sus intereses, ya que la entendían como una ley de privatización aplicada al campo, rescataban como un triunfo el tipo de negociación que se había llevado a cabo para la formulación de esta política, dado que era la primera vez que se aprobaba una ley mediante mecanismos de negociación y de consenso. En este caso particular, habían participado del proceso las organizaciones sociales, el gobierno y las Cámaras de Agricultura y Ganadería que representaban a los grandes propietarios. Este hecho fue leído en el interior de la comunidad indígena como una victoria más de su movimiento.

Más allá de estas cuestiones, el factor desencadenante de la participación electoral en el ámbito nacional de las organizaciones indígenas fue la segunda Consulta Popular que convocó el gobierno de Durán-Ballén en 1994. Desde el Ejecutivo se usó este mecanismo democrático como una sali$\mathrm{da}$ a la crisis institucional provocada por el bloqueo del Congreso Nacional a las reformas económicas "neoliberales” del presidente. En la Consulta se preguntó al electorado acerca de una gama de temas, entre los cuales sobresalían preguntas relativas a la seguridad social y los derechos de los trabajadores públicos ${ }^{17}$. Los indígenas, las organizaciones de

14. Entendemos a un movimiento social como a "...un intento colectivo de promover un interés común, o de asegurar un objetivo compartido, mediante la acción colectiva en el exterior de la esfera de las instituciones establecidas..." (Giddens, 1994:678).

15. La participación política convencional se refiere a aquellas “...actividades que tradicionalmente han sido definidas como políticas y que son esperadas de...los... miembros de una sociedad en ciertos períodos, específicamente los electorales, pero también... cuando las instancias de poder necesitan de la reconfirmación del apoyo popular..." (Montero, 1995:95).

16. La posibilidad de participación de candidatos no afiliados a partidos políticos fue sometida a una primera Consulta Popular en 1986, durante el gobierno de León Febres Cordero; pero la reforma no obtuvo la mayoría necesaria para ser aprobada. Según muchos analistas esto se dio porque la consulta se desvirtuó y se convirtió en una "calificación" del gobierno. La convocatoria a Consultas Populares a sido una constante en el último período poliárquico.

17. Las preguntas que interesan para los fines de este artículo son: Pregunta 2. DERECHO A ESCOGER EL REGIMEN DE SEGURIDAD SOCIAL: ¿Debería incorporarse a la Constitución Política una disposición que diga: "Toda persona tiene derecho a escoger libre y voluntariamente tanto el régimen de seguridad social, como sus prestaciones, servicios y el destino de los aportes, para que estén a cargo del Instituto 
izquierda y los sindicatos públicos encabezaron la oposición a las reformas que planteaba el gobierno y que según ellos debían ser rechazadas por su contenido «neoliberal». Así, la derrota de las tesis del gobierno dio a estos grupos la sensación de que su proyecto político estaba listo para ser sometido al electorado nacional pues se tomó a ese resultado como un éxito propio, como un triunfo de las tesis estatistas y antineoliberales que ellos defendían. Según uno de los dirigentes de Pachakutik ${ }^{18}$ en ese momento se tenía la sensación de que el país optaría por una propuesta de izquierda, antineoliberal y antiprivatizadora. A ese factor, además, habría que añadirle la participación dentro del movimiento social de muchos sectores que habían estado vinculados tradicionalmente a partidos con experiencia electoral, el cálculo político de algunos dirigentes indígenas y la presencia de un solo candidato en representación del centro-izquierda para las siguientes elecciones nacionales en 1996.

A pesar de tantos elementos que parecían ser beneficiosos para el debut electoral del movimiento indígena, la discusión dentro de la CONAIE continuaba. En su interior se enfrentaban dos posiciones: la de los dirigentes de la sierra y la de los líderes de la amazonía. La primera proponía la formación de una organización plurinacional que no llegara a conformarse como un partido político y la segunda postulaba la creación de un Partido Indio.

La discusión giraba en torno a tres consideraciones: a) la necesidad de contar con una forma de proyección política al conjunto de la sociedad; b) el ejercicio de formas de gestión alternativas y la consolidación de los poderes locales y c) la combinación de la acción institucional con la extrainstitucional (Barrera, 1998).

En el Congreso extraordinario de la CONAIE, realizado en enero de 1996, se decidió la participación electoral en el ámbito nacional privilegiando a los sectores que proponían pasar a la participación convencional pero sin llegar a convertirse en un partido político, aprovechando de ese modo la apertura que las élites partidarias habían dado al sistema político a partir de la eliminación de la exigencia de que las candidaturas electorales fueran presentadas únicamente por partidos políticos. Así, los sectores indígenas percibieron que con el cambio de legislación se abría un espacio político que ellos podían ocupar. En este escenario, un mes más tarde se constituyó el Movimiento de Unidad Plurinacional Pachakutik-Nuevo País (MUPP-NP), integrado por la CONAIE, la Coordinadora de Movimientos Sociales (CMS), los trabajadores petroleros, el Movimiento de Ciudadanos por un Nuevo País, que auspiciaba la candidatura presidencial de Fredy Elhers ${ }^{19}$ y pequeños grupos de izquierda (cristianos, trostkistas, miristas, entre otros). Pachakutik se originó como una nueva alianza de izquierda y de sectores críticos al modelo económico y estatal, que según Barrera (1998), buscaba resignificar el campo de lo político en torno a una serie de ideas fuerza:

a. independencia y autonomía de las instituciones y organizaciones partidarias tradicionales del sistema político;

b. espacio de encuentro entre el movimiento campesino indígena y los usuarios rurales con los sectores urbanos;

c. presentación de un programa para la sociedad;

d. propuesta ética de la actividad política.
De esta manera, las reivindicaciones políticas del sector indígena alcanzaron magnitud nacional gracias a la alianza con el Movimiento Ciudadanos por un Nuevo País que proponía un discurso ético de la política, que facilitaba la proyección «nacional» del movimiento indígena al integrar demandas multisectoriales y que presentaba un programa próximo a la izquierda, lo cual lo ubicaba claramente en un espacio del mapa ideológico ecuatoriano. Es así que al producirse la alianza entre Pachakutik y Nuevo País, Elhers logra ingresar a la zona rural y los sectores indígenas obtienen el apoyo de los sectores urbanos y, en particular, de los intelectuales progresistas.

Como mencionamos anteriormente y siguiendo los supuestos presentados por Bartolini y Mair (1990), la primera traducción política de ese conflicto se dio en los comportamientos de los sectores indígenas, por ejemplo, con el empleo de los modos alternativos de acción política (cierre de carreteras, toma de las iglesias, manifestaciones y protestas). Con la formación de MUPP-NP logra, por una parte, traducirse a nivel de organizaciones políticas la línea de tensión étnica y, por otra parte, adquiere nueva forma la línea de división ideológica en su cara izquierda. Así se da la alianza de clivajes (étnico, ideológico y, quizás habría que mencionar el ético) o, lo que es lo mismo, la traducción política de tensiones que se mantenían latentes y que pasan a convertirse en un conflicto central al interior del sistema político.

Luego de las elecciones presidenciales de 1996 el presentador de televisión pierde el protagonismo que tenía en la alianza y los sindicatos públicos, especialmente de trabajadores petroleros (el sector más representativo de la CMS), y los sectores indígenas pasan a controlar el Movimiento. A pesar de ello, vale la pena resaltar el carácter heterogéneo de las propuestas del Movimiento de Unidad Plurinacional Pachakutik-Nuevo País. Es importante destacar que no representa únicamente los intereses de los sectores indígenas, aunque es cierto que estos son un sector estratégico dentro del movimiento, y que muchas de la reivindicaciones políticas que hace Pachakutik están dentro

Ecuatoriano de Seguridad Social o de otra institución privada o pública. El sistema de seguridad social se fundará en los principios de solidaridad y libre competencia?”. Los resultados en el ámbito nacional fueron los siguientes: por el SI: 1.200.491 y por el NO: 1.824.636. Pregunta 4. PARALIZACION DE LOS SERVICIOS PUBLICOS: ¿ Debería incorporarse a la Constitución Política una disposición que diga: "Prohíbese, aun en el caso de huelga, la paralización de los servicios de salud, educación, transporte, agua potable, energía eléctrica, combustibles y telecomunicaciones. La violación de este precepto será considerada como una infracción penal y sancionada de conformidad a la ley?". Los resultados a nivel nacional fueron los siguientes: por el SI: 1.184 .321 y por el NO: 1.799.785. Pregunta 10. ELIMINACION DE PRIVILEGIOS EN EL SECTOR PÚBLICO. Se sustituirán los dos últimos incisos del art. 128 de la Constitución Política por lo siguiente: “...la ley garantizará los derechos y establecerá las obligaciones de los servidores públicos en el servicio civil y la carrera administrativa, sin admitir privilegios. En el sector público solo los obreros estarán amparados por el Código de Trabajo. Los resultados a nivel nacional fueron por el SI: 1.342 .446 y por el NO: 1.712.452.

18. Comunicación con los autores, noviembre de 1998.

19. Este último era un presentador de un programa semanal de televisión que no había realizado política militante, que aparecía como un outsider sin los vicios propios de los políticos y que tenía altos niveles de intensión de voto incluso antes de que se consolide la alianza. 
de la agenda de las organizaciones indígenas, pero en el Movimiento también son relevantes las demandas que hacen los otros sectores que hemos mencionado.

\section{c) Etapa de incorporación institucional (promoción de la incorporación mixta)}

La etapa de incorporación institucional de los sectores indígenas puede describirse en tres ámbitos: la participación electoral, la labor legislativa y la actuación en la Asamblea Nacional Constituyente de 1998 del Movimiento Unidad Plurinacional Pachakutik-Nuevo País.

\section{- Participación Electoral:}

La primera vez que MUPP-NP participó electoralmente fue en los comicios de 1996. Hasta ese momento, nunca un movimiento o partido que reivindicara en su agenda las cuestiones indígenas ${ }^{20}$ había tenido participación en los mecanismos de elección de candidatos establecidos por la Constitución y las reglas de los sistemas electorales. Así, la población indígena accedía por primera vez a una forma de representación política con sus propios dirigentes y sus propias organizaciones (Guerrero, 1997:60). En esa elección MUPP-NP presentó candidatos para todo tipo de cargos: presidente y vicepresidente, diputados nacionales y provinciales, alcaldes cantonales, prefectos provinciales, concejales cantonales y consejeros provinciales.

En la primera vuelta de la elección presidencial realizada el 19 de mayo de 1996, el binomio conformado por Fredy Elhers y Rosana Vinueza de Tama obtuvo el 20,60 por ciento de los sufragios, lo cual significó 785.124 votos válidos situándose en el tercer lugar (por detrás del Partido Roldosista Ecuatoriano y el Partido Social Cristiano) (Cuadro V). A pesar de ser éste su debut electoral nacional, Pachakutik consiguió superar a la Democracia Popular que sólo obtuvo el 13,47 por ciento de los votos válidos. Al mismo tiempo, en las elecciones legislativas ${ }^{21}$, MUPP-NP consiguió un diputado nacional y siete provinciales (uno en Pichincha, uno en Cotopaxi, uno en Chimborazo, dos en Azuay, uno en Napo y uno en Pastaza) (Cuadro VI), concentrando el mayor número de votos en aquellos lugares con mayor población indígena ${ }^{22}$ y en las ciudades de Quito y Cuenca.

CUADRO V

\begin{tabular}{|l|l|l|l|r|}
\hline \multicolumn{4}{|c|}{ Resultados Electorales MUPP-NP } \\
\hline Tipo de elección & \multicolumn{1}{|c|}{1996} & \multicolumn{2}{c|}{1998} \\
\hline Presidencial: Primera vuelta & 785.124 votos & $20.60 \%$ & 566.917 votos & $14.74 \%$ \\
\hline Fuente: TSE. Elaboración de los autores.
\end{tabular}

Dos años después, en las elecciones presidenciales realizadas el 31 de mayo de 1998, la fórmula presentada por el Movimiento indígena, la Coordinadora de Movimientos Sociales y el Movimiento Independiente Ciudadanos para un Nuevo País (MICNP) obtuvo el 14,74 por ciento de los votos válidos, esto es, 566.917 de los sufragios, con lo que la fuerza descendió un lugar en comparación a los resultados obtenidos en la elección presidencial anterior. Así, en ninguna de las dos contiendas electorales, un candidato de MUPP-NP pudo competir en la segunda vuelta electoral.
En tanto, como se observa en el Cuadro VI en las elecciones legislativas realizadas ese mismo día, MUPP-NP obtuvo dos diputados nacionales (en alianza con el Partido SocialistaFrente Amplio) y cinco provinciales (uno en Bolívar, uno en Cotopaxi, uno en Imbabura, uno en Morona-Santiago y uno en Napo).

\begin{tabular}{|c|c|c|c|c|}
\hline \multicolumn{5}{|c|}{ Resultados Electorales IIL PP-NP } \\
\hline Tipo de elección & \multicolumn{2}{|c|}{$1996^{*}$} & \multicolumn{2}{|c|}{ 1998** } \\
\hline Legislativa & $\begin{array}{l}\text { Diputados } \\
\text { Nacionales } \\
\end{array}$ & $\begin{array}{l}\text { Diputados } \\
\text { Provinciales } \\
\end{array}$ & \begin{tabular}{|l|} 
Diputados \\
Nacionales \\
\end{tabular} & $\begin{array}{l}\text { Diputados } \\
\text { Provinciales } \\
\end{array}$ \\
\hline & 1 & 7 & $\begin{array}{r}2 \\
\end{array}$ & 5 \\
\hline
\end{tabular}

En el ámbito provincial, el MUPP consiguió ubicar un consejero provincial en Morona Santiago, otro en Napo y otro en Cotopaxi. En cuanto al nivel municipal, la alianza MUPP-NP obtuvo un concejal en Nabón (Azuay), dos en Guaranda (Bolívar), dos en Caluma (Bolívar), uno en Suscal (Cañar), uno en Pujilí (Cotopaxi), uno en Saquisilí (Cotopaxi), dos en Guamote (Chimborazo), uno en Cotacachi (Imbabura), uno en Gualaquiza (Morona-Santiago), dos en Santiago (Morona-Santiago), dos en Logroño (Morona- Santiago), uno en Huamboya (Morona-Santiago), dos en Taisha (Morona-Santiago), uno en Tena (Napo), dos en Archidona (Napo), uno en Loreto (Napo). En alianza con otros partidos y/o movimientos, el MUPP ha logrado ubicar diferentes dignidades. En alianza con la ID y PS-FA: un consejero provincial en Azuay, un concejal municipal en Cuenca, dos concejales municipales en Yacuambí (ZamoraChinchipe). En alianza con la ID, PS-FA, MICNP (Lista 21): un concejal municipal en Yanzatza (Zamora-Chinchipe). En alianza con MICNP y PS-FA: un concejal en Ibarra (Imbabura) y un concejal municipal en Saraguro (Loja). En alianza con la ID: un concejal en Aguarico (Napo). En alianza con la DP: un concejal en Mera (Pastaza), un concejal en Santa Clara (Pastaza), dos en Arajuno (Pastaza). Con la ID y la DP: un concejal en Sucumbíos (Sucumbíos).

Lo local ha sido planteado desde Pachakutik como punto de partida de una estrategia de construcción de un nuevo modelo de gestión democrática y participativa para la resignificación de la relación entre Estado y Sociedad. Además, el énfasis en el espacio de lo local ha facilitado la argumentación étnica y cultural. Como mencionamos anteriormente, el mayor número de población indígena se encuentra en el sector rural campesino (la zona de la sierra central y las provincias amazónicas) lo que conduce a que el componente étnico del voto a Pachakutik sea a nivel local o regional a diferencia del nivel nacional donde el voto está más vinculado a intelectuales y sectores medios progresistas.

20. Si bien muchos de los partidos incluyen el tema indígena dentro de sus planteamientos y ofertas electorales, es la primera vez que se da una representación orgánica.

21. En cuanto a los resultados cantonales y municipales alcanzados por MUPP-NP en las elecciones de 1996 no ha sido posible presentar dicha información debido a las dificultades para exponerlas por cargos de representación.

22. Esto no significa que en todos los distritos con presencia indígena los candidatos de MUPP-NP hayan obtenido representación. 


\section{- Presencia en el Congreso Nacional}

El bloque del movimiento en el Congreso para el período 1996-1998 estuvo formado por Luis Macas, Miguel Lluco, Napoleón Saltos, José Avilés, Leonidas Iza, Miguel López Moreno, Rosendo Rojas Reyes y Hector Villamil. En tanto, en el período 1998-2003 el bloque estará integrado por Nina Pacari Vega (quién en el primer año de legislatura actuará como Segunda Vicepresidente del Congreso Nacional), Kaizer Arévalo (Jefe de Bloque), Valerio Grefa, Miguel Pérez, Antonio Posso y Luis Talahua. Los datos presentados muestran que ninguno de los diputados del primer período revalidó su escaño en la legislatura actual.

Según la Investigación sobre Elites Parlamentarias Iberoamericanas (1997) y el análisis de los datos presentados por Mateos y Alcántara (1998), los diputados de Pachakutik del período legislativo 1996-1998 manifestaron pertenecer en su mayoría a una clase social baja (62\%), tener una situación económica modesta $(87 \%)$, un nivel de ingresos menor a los 20.000 dólares anuales $(74 \%)$ y una situación económica similar a la de su padre cuando él era pequeño $(50 \%)$.

Al comparar las respuestas de los diputados del movimiento con las de los otros partidos analizados en la investigación encontramos importantes diferencias. En relación a la clase social, mientras la mayoría de los diputados de Pachakutik se consideraron de clase baja, la mayor parte de los diputados de los demás partidos indicaron ser de clase media-alta (71\% del PSC, 70\% de la DP, 69\% del PRE). En cuanto a la situación económica, los diputados de MUPP. NP señalaron que ésta era modesta mientras grupos importantes de los otros partidos indicaron que la suya era acomodada ( $54 \%$ del PSC, $50 \%$ del PRE y $50 \%$ de la DP). En tanto, con respecto al nivel de ingresos, encontramos diferencias entre los grupos, que podrían explicarse una vez más por las diferencias económicas del país. Así, mientras los diputados de Pachakutik señalaron sus ingresos como menores a 20.000 dólares anuales, un sector importante de la DP (40\%) los ubicó por encima de los 20.000 mientras que los diputados del PSC (44\%), tradicionalmente de familias con recursos económicos, y del PRE (77\%), relacionados especialmente con el sector exportador de la costa también de altos ingresos, se posicionaron por encima de los 40.000 dólares anuales. Por último, los diputados del MUPP-NP señalaron que su situación económica era similar a la de sus padres cuando eran niños mientras que los diputados de los demás partidos indicaron que era mejor (75\% PSC, 70\% DP y $64 \%$ PRE).

En la escala de ubicación ideológica, los diputados de este movimiento ubicaron a Pachakutik hacia la izquierda del espectro político con una indicador de 3.4 mientras que los diputados de los otros partidos (DP, PRE, PSC y DP) lo consideraron como un partido de centro, en la posición 5.2 de una escala de diez puntos.

Los diputados de Pachakutik sostuvieron que habían sido elegidos como representantes debido a que ninguna de las otras opciones políticas convencía a los electores (75\%) mientras que los diputados de los otros partidos señalaron que la razón principal que los llevó a ocupar un escaño había sido la simpatía personal ( $50 \%$ de la DP, $42 \%$ del PSC y $36 \%$ del PRE). Este dato es coherente con la idea fundacional del movimiento que sostenía la necesidad de erigirse como un espacio político alternativo a las opciones partidarias tradicionales. En este sentido, al consultársele acerca de la vinculación entre partidos y sociedad, ninguno de los diputados de Pachakutik sostuvo que los ciudadanos se identifican en la actualidad con los partidos políticos. Por el contrario, un grupo mayoritario $(62 \%)$ consideró que existe un progresivo alejamiento entre sociedad y partidos y el resto de los consultados (38\%) directamente destacó el distanciamiento de las estructuras partidarias de los ciudadanos (al mismo modo que un $46 \%$ del PSC, un $40 \%$ de la DP y un $22 \%$ del PRE).

En el actual período, los diputados de Pachakutik son miembros principales de las Comisiones de lo Laboral y lo Social (Pérez); de lo Económico, Agrario, Industrial y Comercial (Talahua); de Gestión Pública y Universalización de la Seguridad Social (Vega); de Salud, Medio Ambiente y Protección Ecológica (Arévalo); de Educación, Cultura y Deportes (Posso); Asuntos Indígenas y otras etnias (Grefa). Solo una de estas Comisiones, la de Asuntos Indígenas, es presidida por un diputado de Pachakutik.

De la revisión de la actuación legislativa del Movimiento en los dos últimos períodos de gestión legislativa se puede inferir que su posición tuvo ciertos toques étnicos a través del tratamiento de temas fundamentales para los indios, como la tierra y las reformas al modelo de Estado. Esto llama la atención si se considera que MUPP-NP no representa sólo las demandas étnicas sino también los intereses de ecologistas, mujeres, unión de trabajadores y sectores de izquierda. También en el primer período de actuación legislativa, pusieron gran énfasis en la lucha contra la corrupción y la fiscalización del gobierno de Abdalá Bucaram desde la Comisión de Fiscalización que en ese momento estaba presidida por el diputado Napoleón Saltos. En el Cuadro VII se exponen los proyectos presentados por los legisladores a nivel de bloque y a nivel individual en ambos períodos legislativos.

CUADRO VII

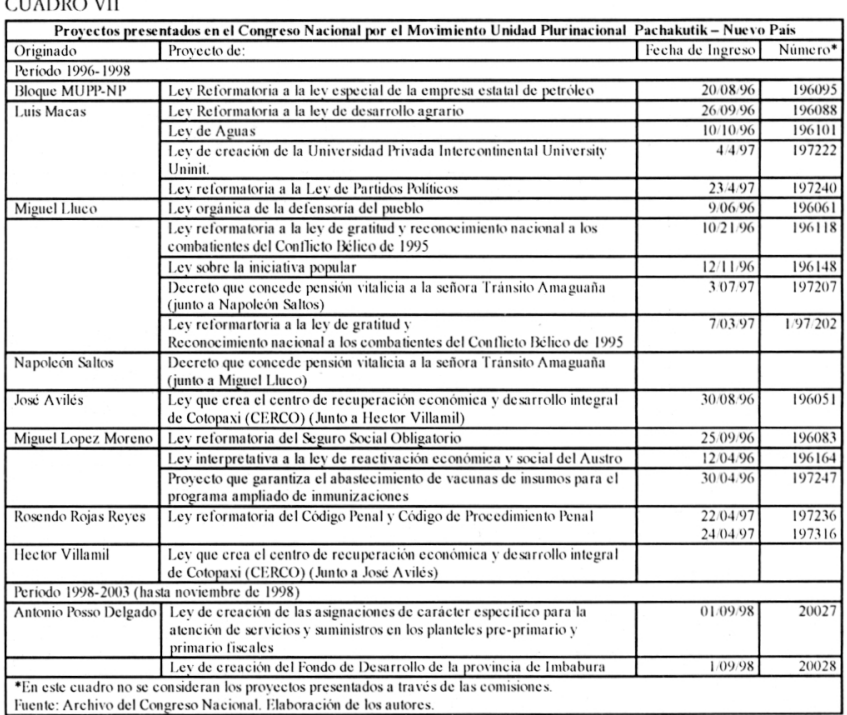




\section{- Actuación en la Asamblea Constituyente de 1998}

En 1989 la CONAIE planteó la necesidad de convocatoria a una Asamblea para reformar la Constitución. En junio de 1997, ECUANUARI presentó una publicación sobre los "Derechos de los Pueblos Indígenas y Propuesta Política de la Nacionalidad y los Pueblos Quichuas del Ecuador" que explicaba las propuestas básicas de la organización indígena para dicha reforma. Tras la crisis de febrero de 1997 y en el transcurso del interinato de Fabián Alarcón se convocó a una Asamblea Constituyente, en la que los sectores indígenas organizados tuvieron una participación activa. El movimiento envió 10 representantes a una Asamblea de setenta miembros donde hizo alianza con la Izquierda Democrática y el Partido Socialista - Frente Amplio en lo que se denominó la "Concertación Democrática”. Los asambleístas fueron Nina Pacari (Chimborazo), José Vega (Cotopaxi), Gabriel Galarza (Bolívar), Kayser Arévalo y Felipe Chimpi (Morona Santiago), Angel Ortiz (Zamora), Julio César Trujillo (Pichincha), Enrique Ayala (Imababura), Hugo Ruiz (Carchi) y Luis Angel Bermeo (Sucumbíos). A pesar de las alianzas, el movimiento indígena prefirió concentrar su acción en el impulso de su proyecto étnico-nacional, en detrimento del liderazgo de la corriente progresista (Buendía e Iturralde, 1996).

Los movimientos sociales y políticos consiguieron introducir en el texto de la Constitución muchas de sus demandas particulares en el ámbito de los derechos civiles y políticos: derechos humanos, ambientales, de los pueblos

CUADRO VIII

\begin{tabular}{|c|c|c|}
\hline \\
\hline Tema & Propuesta de Reforman & Incluida en la Constitución Pollifica de 1998* \\
\hline Esta do $y$ Nacion & 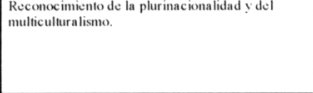 & 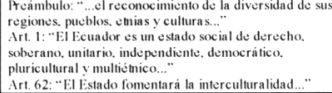 \\
\hline Organizacíín del Estado & 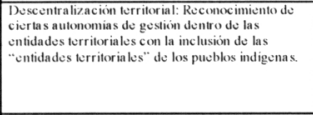 & 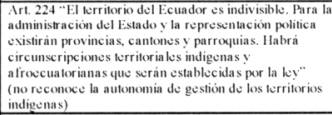 \\
\hline Compelencias del Estado & 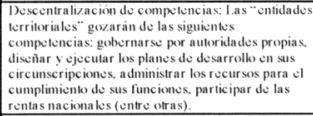 & \begin{tabular}{|l|} 
(no lo incorpora) \\
\end{tabular} \\
\hline Neodiclo de Desarrollo & Desarrollo social (modelo allermativo) & 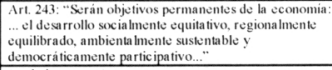 \\
\hline Democracin & Democracia participativa & (no lo incorpora) \\
\hline Idioma & $\begin{array}{l}\text { Declaracion del quichua como idioma oficial (enn } \\
\text { iguan ldad con el castivilano) }\end{array}$ & 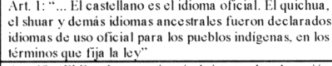 \\
\hline Educación & Bilingaus & 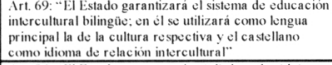 \\
\hline $\begin{array}{l}\text { Representantesy } \\
\text { Auloridades }\end{array}$ & 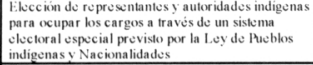 & 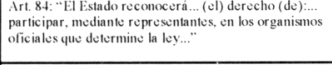 \\
\hline Siguro Social & Derecho al Siguro Social de Na cimal lidades & 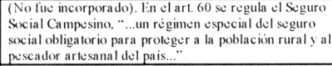 \\
\hline $\begin{array}{l}\text { Derechos colectivosy } \\
\text { sociales }\end{array}$ & 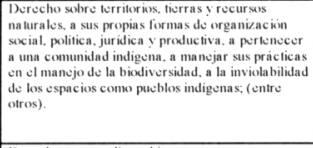 & 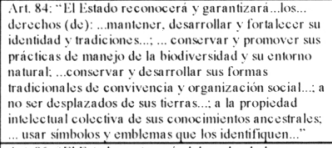 \\
\hline Medio ambicnle & Derectho a tur medio a ambirinte same & 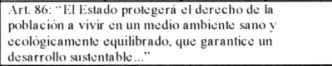 \\
\hline Consumidor & Derechos de los consumidores & 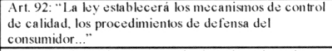 \\
\hline Derechos Económic as & 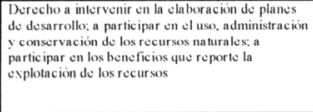 & 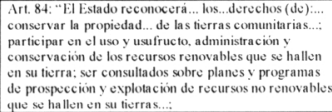 \\
\hline Salud & $\begin{array}{l}\text { Dorecho a a utilización de medicima occidental } \\
\text { como medicina alturnativa }\end{array}$ & 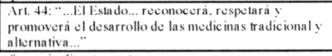 \\
\hline
\end{tabular}

indios y afroecuatorianos, de las mujeres, de las minorías sociales, de los consumidores, de los discapacitados, pero no lograron impulsar las reformas políticas y económicas estructurales que un primer momento pretendían. Esto puede observarse en el Cuadro VIII donde se presentan las propuestas realizadas por el movimiento indígena para la reforma y su posterior situación en el texto constitucional.

Por último, a pesar de la incorporación institucional en diferentes ámbitos, el movimiento continúa empleando en la actualidad, aunque más esporádicamente, modos alternativos de acción política siendo muestra de ello el Paro Indígena y Campesino realizado en agosto de 1997 en defensa del Seguro Social Campesino, la Marcha «Todas las Voces en la Constitución» en octubre de 1997 y el cierre de carreteras en apoyo del Paro Nacional del 1 de octubre de 1998 organizado contra las medidas económicas del presidente Jamil Mahuad. Además, cabe mencionar la influencia que el movimiento indígena tuvo, junto a los partidos políticos tradicionales, en la caída del gobierno de Abdalá Bucaram en febrero de 1997. La cuota de poder obtenida de esa participación se materializó durante el gobierno interino de Fabián Alarcón con la creación de un organismo gubernamental que se denominó Consejo de Planificación y Desarrollo de los Pueblos Indios y Negros, que en ese período fue presidido por la actual diputada y Vicepresidenta segunda del Congreso Nacional, Nina Pacari y en la nominación del Ministro de Agricultura y Ganadería el sociólogo Manuel Chiriboga ${ }^{23}$.

\section{ALGUNAS CARACTERÍSTICAS DE LA PARTICI- PACIÓN POLÍTICA DE LOS INDÍGENAS EN EL ECUADOR}

Tratar de asignar un estatuto específico, de acuerdo a los conceptos de la teoría política, al tipo de organización que es el Movimiento de Unidad Plurinacional PachakutikNuevo País, resulta una tarea complicada. En rigor se ajusta al concepto de partido ${ }^{24}$, pero sus dirigentes insisten en negar esa denominación y sostienen que son un movimiento. En este sentido, Pachakutik no cuenta con una organización formal y jerarquizada, lo cual se presenta como un mecanismo de resistencia interna al proceso de institucionalización e inserción total al espectro político. Siendo rigurosos con los presupuestos de Panebianco (1982), estaríamos ante un "partido incipiente" dado que precisamente éstos nacen con estructuras débiles y como representación de intereses de bases. A medida que pasa el tiempo, existen mayores posibilidades de que la organización se vaya fortaleciendo y sus miembros terminen aceptando el rótulo de partido político. Aunque en el caso de

23. Chiriboga no pudo asumir su cargo porque fue objetado por las cámaras empresariales. Los hacendados presionaron sobre el gobierno argumentando la ideología del sociólogo y no se lograron acuerdos sobre esta candidatura.

24. Entendemos a un partido político como a “... toda asociación voluntaria perdurable en el tiempo, dotada de un programa de gobierno de la sociedad en su conjunto, que canaliza determinados intereses sectoriales y que aspira a ejercer el poder político o a participar en él mediante su presentación reiterada a los procesos electorales..." (Cotarelo, 1985:14). 
Pachakutik, encontramos un problema de identidades (o auto-reconocimiento) vinculado a cómo los miembros de una organización definen a su agrupación. Así, en la práctica, ese problema no existe ya que más allá del nombre con que quiera denominárselo, esa organización cumple determinadas funciones en el sistema político que son atribuibles a los partidos políticos. La no utilización de ese término tiene un papel simbólico que permite a las élites del movimiento continuar señalando su malestar con el sistema político.

Para la organización del movimiento se trasladaron las lógicas de las agrupaciones indígenas-campesinas a la estructura de funcionamiento. Ese tipo de organización se caracteriza por el escaso distanciamiento entre bases y líderes, por la presencia de mecanismos colectivos en la toma de decisiones, por una estructura poco burocratizada y de manejo formal y por la valoración a la iniciativa de los miembros. En la relación con otras organizaciones, podría señalarse a Pachakutik como el brazo político de la CONAIE. La vinculación de esta con Pachakutik se ha dado a través de un Consejo Político que fue creado para evitar la excesiva dependencia entre las dos estructuras. Más allá de ello, nos encontramos ante el caso de "una organización que controla a un partido político" (Panebianco, 1982). La actuación política de Pachakutik ha tenido características corporativas ${ }^{25}$ dado que ha centrado su accionar en la defensa de los intereses de un grupo definido de acuerdo a identidades específicas (indígenas, petroleros, usuarios del seguro social campesino). A pesar de que el movimiento representa demandas e intereses de distintos sectores, no ha logrado integrar las propuestas a niveles interclasistas como las que realizan los partidos políticos tradicionales.

El eje de su movilización política ha sido la redefinición del modelo del Estado nacional ecuatoriano, por medio del planteamiento de la plurinacionalidad. En el interior de esta propuesta se presentan al mismo tiempo la transformación del estado como de la sociedad. En cuanto al Estado, la «plurinacionalidad» no supone la creación de dos estados paralelos, como señala Kowii (1997), pero sí cuestiona su carácter homogéneo ya que eso significa reconocer sólo la existencia de una única cultura nacional. La plurinacionalidad implica reconocer la diversidad de las once nacionalidades ecuatorianas en el diseño del aparato estatal (Quichua, Shuar-Achuar, Chachi, Tsachi, Siona-Secoya, Huaorani, Cofan, Awa, Epera y Zaparo). En cuanto a la sociedad, la «plurinacionalidad» es «... el nacimiento de una nueva sociedad... orgullosa de su diversidad cultural...» (Kowii, 1997) y defensora de los recursos estratégicos ${ }^{26}$ del país como un bien común.

El movimiento incorpora también un nuevo "lenguaje" al discurso político ecuatoriano. Términos como diferencia, autonomía, plurinacionalidad, culturas, historias, racionalidad, biodiversidad adquieren nuevos significados en el contexto político. Es como si esos términos se politizaran en un escenario distinto y se potenciaran, facilitando así la creación de espacios políticos para nuevos actores sociales como las mujeres, los homosexuales y los ecologistas. Del mismo modo, el movimiento consiguió la pluralización del concepto de nación, elemento que como hemos visto se ha plasmado en el texto constitucional escrito por la Asamblea Constituyente de 1998.

Asimismo, el objetivo de combinar la acción institucional con la extra-institucional, planteados en los orígenes de Pachakutik, ha sido el motor de la actuación política. Este objetivo conllevaba en sus inicios dos tipos de manifestaciones complementarias: por una parte, las actividades como movimiento político (es decir, canalizador de demandas en las instituciones políticas) y, por otra parte, las actuaciones como movimiento social y cultural (esto es, portador de reivindicaciones, derechos y valores que profundizarían la democratización de la sociedad). Hasta el momento, ese objetivo de actuación política junto a sus manifestaciones complementarias han dado resultados satisfactorios desde el punto de vista de los espacios de poder y relevancia política que han obtenido en los últimos años.

\section{CONSIDERACIONES FINALES}

La vocación modernizante del Estado ecuatoriano de las últimas décadas, expresada en la implementación de políticas de modernización hacia el sector indígena y de liberalización política (Reforma Agraria, Proyectos de Desarrollo, voto para los analfabetos, presentación de candidatos por fuera de los partidos) ha supuesto una transformación importante de la postura tradicional del Estado y de las élites políticas hacia este sector, buscando la incorporación de esta población al sistema político. La modernización ha beneficiado la incorporación de los sectores indígenas a la vida política dado que han fomentado la organización de los indígenas (condición necesaria para acceder a la tierra); la formación y capacitación de una nueva élite, la educación de los analfabetos y la urbanización de sectores tradicionalmente rurales. Así, el cambio de actitud en este sector sería consecuencia de la expansión de la educación, del alfabetismo, la intensificación de la comunicación entre las comunidades y el Estado, entre otros elementos. Tras los distintos pasos dados en el proceso de modernización, el sector indígena fue tomando conciencia de su situación social y de su capacidad para impulsar los cambios. En este marco, las élites buscaron modificar su tradicional actitud auto-excluyente, de carácter pasivo, para convertirse en agentes de cambio.

25. Se usa el concepto de acuerdo a los planteamientos de Philippe C. Schmitter (1992), a partir de una relectura de las teorías corporativas clásicas, crea el concepto de corporatismo al que define como "... un sis tema de representación de intereses en el cual las unidades constitutivas se organizan en un limitado número de categorías singulares, compulsatorias, no recurrentes, ordenadas jerárquicamente y diferenciadas funcionalmente, reconocidas y autorizadas... por el Estado, y a las que se les concede un explícito monopolio de la representación dentro de sus respectivas categorías a cambio de observar ciertos controles en la selec ción de sus líderes y en la articulación de sus demandas y apoyos...”(46)

26. La idea de recursos estratégicos está muy vinculada a la doc trina de la seguridad nacional y, últimamente desde otra visión, está siendo defendida por los grupos de izquierda pues como sector estratégico se considera a la electricidad, el petróleo, las telecomunicaciones..., esto es, a todo lo privatizable. Así, la noción de recursos estratégicos del Estado da sustento a los detractores de las privatizaciones y de las políticas neoliberales en boga. 
Esta transformación en la percepción de los indios fue primero con respecto al Estado y luego al sistema político. A los primeros intentos de incorporación del Estado "desde dentro", le siguió un proceso de movilización "desde fuera” por parte de los indígenas, caracterizado por la utilización de modos alternativos de acción política, que estaba ligado a una vocación antisistema del movimiento y a la negación de integración al sistema político por canales institucionalizados. Una vez que las organizaciones indígenas evaluaron la eficacia de

ANEXO I

\begin{tabular}{|c|c|}
\hline \multicolumn{2}{|c|}{ Organizaciones de segundo grado en las provincias de la sierra y año de creación* } \\
\hline Provincia & Año de creación \\
\hline \multicolumn{2}{|l|}{ Provincia del Carchi } \\
\hline Unión de Organizaciones Campesinas del Carchi & 1975 \\
\hline \multicolumn{2}{|l|}{ Provincia de Imbabura } \\
\hline Federación de Indigenas y Campesinos de Imbabura & 1974 \\
\hline Unión de Organizaciones Campesinas de Cotacachi & 1979 \\
\hline Comite Pro Mejoras de Ilumán & 1979 \\
\hline Unión de Cominidades para el Desarrollo & 1986 \\
\hline Unión de Comunidades de Atuntaqui & inicio de los 80 \\
\hline Unión de Comunidades de Angochagua y la Esperanza & inicio de los 80 \\
\hline Unión de Campesinos de San Pablo & Lin de los 60 e inicio de los 70 \\
\hline Asociación Agrícola Quinchuquí & 1981.82 \\
\hline Asociación Agricola San Miguel & inicio de los 80 \\
\hline Asociación de Trabajadores Agrícolas Casco.Valenzuela & $\mathrm{s} / \mathrm{t}$ \\
\hline Unión de Comunidades Indigenas de González Suarez & 1980 \\
\hline Unión de Comunidades de Cuellaje & 1986 \\
\hline \multicolumn{2}{|l|}{ Provincia de Pichincha } \\
\hline Pichincha Riccharimi & fin de los 70 \\
\hline Unión de Organizaciones Campesinas de Cangahua & 1978 \\
\hline Unión de Comunidades Indigenas de Cochapamba & 1984 \\
\hline Unión de Comunidades de Pedro Moncayo & 1984 \\
\hline \multicolumn{2}{|l|}{ Provincia de Cotopaxi } \\
\hline Cabildo Mayor de Cusubamba & fin de los 70 e inicio de los 80 \\
\hline Unión de Cabildos de Zumbahua & 1988 \\
\hline Jatun Ayllu & 1982 \\
\hline Unión de Organizaciones Campesinas del Norte de Cotopaxi & 1979 \\
\hline Unión de Organizaciones Campesinas de Mulalillo & 1983.84 \\
\hline Movimiento Indigena de Cotopaxi & $\mathrm{s} / \mathrm{t}$ \\
\hline Asociación de Trabajadores Agricolas de Cotopaxi & $\mathrm{s} / \mathrm{I}$ \\
\hline Asociación de Campesinos & década de los 80 \\
\hline \multicolumn{2}{|l|}{ Provincia de Tungurahua } \\
\hline Movimiento Indigena de Tungurahua (MIT) (origen eclesial) & inicio de $\operatorname{los} 60$ \\
\hline \multicolumn{2}{|l|}{ MIT Centro Atocha (continua la vinculación con la iglesia católica) } \\
\hline MIT & 1984 \\
\hline Organización Cristobal Pajuña & 1978 \\
\hline Unión de Organizaciones Campesinas de Pilahuin & 1986 \\
\hline Organización Santa Rosa & $\mathrm{s} / \mathrm{t}$ \\
\hline Organización de Pacha & 1986 \\
\hline Unión de Organizaciones Campesinas del Norte de Tungurahua & 1978 \\
\hline Unión Indigenas Salasacas & 1984 \\
\hline Unión de Indigenas de Tungurahua & 1986 \\
\hline Unión Nacional de Indigenas Campesinos del Ecuador, tilial Tungurahua & 1984-88 \\
\hline \multicolumn{2}{|l|}{ Provincia de Bolivar } \\
\hline Runacunapaj Yachanahuasi-Simiatug & 1972.74 \\
\hline Federación Campesina de Bolivar & 1980 \\
\hline Unión y Progreso & 1983 \\
\hline \multicolumn{2}{|l|}{ Provincia de Chimborazo } \\
\hline Unión de Asociaciones Agricolas de Columbe & 1973 \\
\hline Jatum Cabildo de Guamote & 1973.77 \\
\hline Federación de Cabildos de Chunchi & 1974 \\
\hline Federación de Cabildos de la Parroquia Cacha & mediado de los 70 \\
\hline Unión de Comunidades Campesinas de San Juan & 1978 \\
\hline Unión de Comunidades Indigenas de Flores & 1978 \\
\hline Unión Campesina de Licto & $s / \mathrm{t}$ \\
\hline Unión de Cabildos de Calpi & $\mathrm{s} / \mathrm{f}$ \\
\hline Unión de Organizaciones Campesinas de Quimiag & 1980 \\
\hline Unión de Organizaciones de Penipe & 1981 \\
\hline Unión de Comunidades de Pangor & $s / \hat{f}$ \\
\hline Federación de Comunidades de Alausi & $\mathrm{s} / \mathrm{f}$ \\
\hline Federación de Comunidades de Pungala & mediado de los 80 \\
\hline Unión de Organizaciones Campesinas de Aloa & 1972 \\
\hline Organizaciones de Comunidades de Sicalpa & mediado de los 80 \\
\hline Federación Indigena de Chimborazo & $\mathrm{s} / \mathrm{f}$ \\
\hline Moviniento Indigena de Chimborazo & fin de $\operatorname{los} 70$ \\
\hline Federación de Organizaciones Indigenas de Chimborazo & $\mathrm{s} / \mathrm{i}$ \\
\hline Asociación Evangélica de Chimborazo & $s / \mathrm{f}$ \\
\hline Federación Campesina Indigena de Leonidas Proaño & $s / f$ \\
\hline Organizaciones Indigena de Mujeres Lorenza Abimañai & $5 / f$ \\
\hline Federación Campesina Autónoma de Chimborazo & 1984 \\
\hline \multicolumn{2}{|l|}{ Provincia de Cañar } \\
\hline Unión Provincial de Comunas y Cooperativas de Cañar & 1976 \\
\hline Provincia del Azuay & \\
\hline UNASAY & 1974 \\
\hline Provincia de Loja & \\
\hline Federación Interprovincial de Indigenas Saraguros Antigua OCIS) & 1975 \\
\hline $\begin{array}{l}\text { * En esta lista no constan todas las organizaciones de segundo grado, pero } \\
\text { va de las organizaciones provinciales y microregionales del Ecuador, espec } \\
\text { gimiento de este tipo de organizaciones. } \\
\text { Fuente: Sánchez- Parga (1989). Elaboración: los autores. }\end{array}$ & $\begin{array}{l}\text { uyen una muestra representati- } \\
\text { nl lo relativo al período de sur- }\end{array}$ \\
\hline
\end{tabular}

los modos alternativos de acción política y las posibilidades que las élites políticas les ofrecían para incorporarse al sistema político sin la necesidad de procesar sus demandas por las estructuras de representación tradicionales, comenzaron a utilizar algunos de los mecanismos que el sistema político les proporcionaba para canalizar su participación.

Este proceso ha sido de naturaleza mixta. Se fue dando tanto desde el Estado, que aún continúa intentando incorporar a ese sector de la población, como desde el Movimiento que de manera paulatina ha aceptado formar parte de algunas de las instituciones del sistema. En este sentido, el camino hacia la plena institucionalidad está en sus comienzos aunque quizás no llegue a la transformación del Movimiento en un partido político, en particular, por el carácter simbólico del rechazo a las instituciones del sistema político. Un sistema que continúa en proceso de democratización y en el que los movimientos indígenas actúan como indicadores de la necesidad de extender la democracia al interior de las instituciones, las prácticas políticas y al conjunto de la ciudadanía.

Por último, cabe mencionar el hecho de que un debate que surge en el plano de las identidades, al interior de la sociedad, logra ingresar al marco institucional del sistema político. En este sentido, se muestra cómo un conflicto de naturaleza social que había permanecido dormido durante mucho tiempo pero que pululaba en la sociedad, logra readaptarse y ser traducido políticamente. Esto es, en definitiva, una muestra de la naturaleza dinámica de esas alianzas y de la necesidad de repensar teóricamente acerca las tensiones estructurales de la sociedad y su traducción al ámbito político.

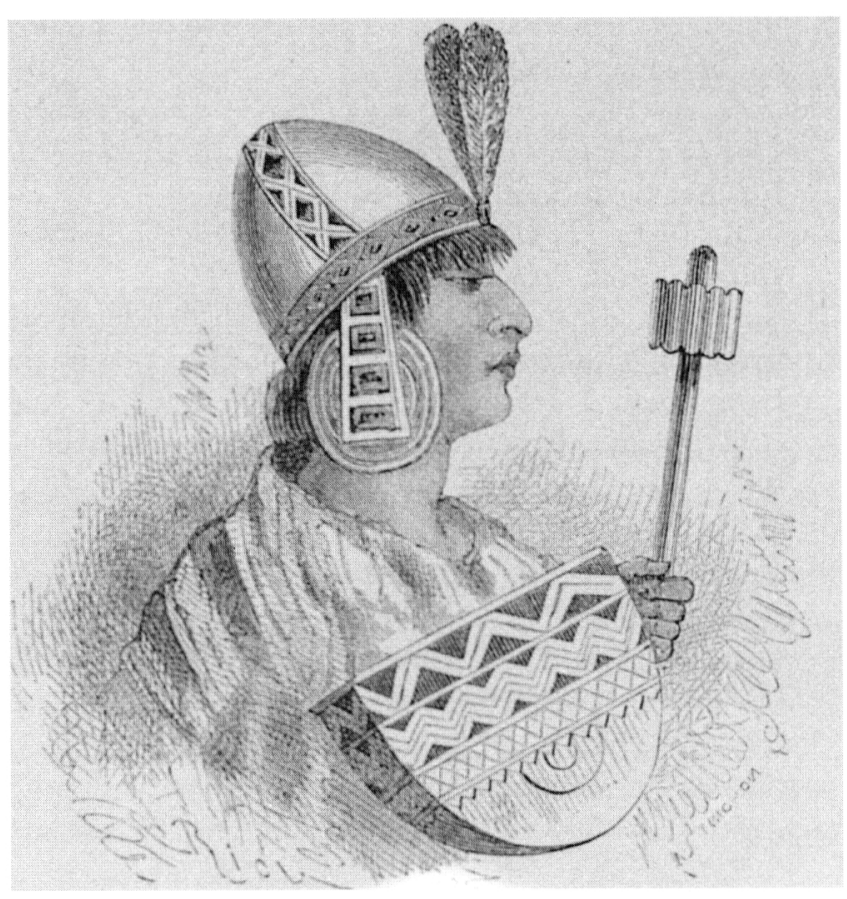

Pacha Ccutic 


\section{BIBLIOGRAFÍA}

AlmeidA, J. (1992): «El mestizaje como problema ideológico». En: AA.VV: Identidades y sociedad. Quito: CELA-PUCE

AlCÁNTARA, M. (1994): Gobernabilidad, crisis y cambio. Madrid: Centro de Estudios Constitucionales.

- (1997): "Se ha fetichizado la reforma política". Entrevista realizada por Felipe Burbano de Lara. Iconos, 3, agosto-octubre, 58-65.

ANDRAGO, A. (1986): "Como indígenas tenemos nuestros planteamientos políticos", Ecuador Debate, diciembre de 1986.

Ayala Mora, E. y otros (1992). Pueblos indigenas, Estado y derecho. Quito: CEN

BARRERA, A. (1998): Pachakutik: entre lo social y lo político. Mímeo.

BARTOLINI, S. Y MAIR, P. (1990): Identity, competition and electoral availability. The Stabilisation of European Electorates 1885-1985. Cambridge: Cambridge University Press.

Bebbington, A. y Ramón, G. (coord.) (1992): Actores de una década ganada: tribus, comunidades y campesinos en la modernidad. Quito: COMUNIDEC.

Buendía, F. E IturRalde, P. (1996): "Condiciones del período. Movimiento de Unidad Plurinacional Pachakutik-Nuevo País". Quito. Septiembre.

Burbano de LARA, F. (1998): Cultura Política y democracia en el Ecuador: una aproximación a nuestros vacios. Quito: CORDES.

Conaie (1997): "Proyecto Político". Quito.

CotARelo, R. (1985): Los partidos politicos. Madrid: Sistema.

ECuanuari (1998): "Derechos de los Pueblos Indígenas y Propuesta política de la Nacionalidad de los Pueblos quichuas del Ecuador". Documento de Base $\mathrm{n}^{0} 1$.

ÉLITES PARLAMENTARIAS IBEROAMERICANAS (1997): Ecuador Vol. 4. Madrid y Salamanca: CIS-Instituto de Estudios de Iberoamérica y Portugal.

EscoBAR, A. (1993): Encountering Development: The Making and Undmaking of the Third World 1945-1992. Northampton: Smith College.

GALO, R. (1998): Los pueblos indígenas y negros del Ecuador. Sintesis Social, 3. Quito: SIISE

GUERRERO, A. (1997): "Las formas ventrílocuas de representación”. Entrevista realizada por Felipe Burbano de Lara. Iconos, 1, febrero-abril, 60-66.

- (1998): "Ciudadanía, frontera étnica y compulsión binaria”. Iconos, 4. Quito: FLACSO

GuidDEns, A. (1994): Sociología. Madrid: Alianza.

Huntington, S. (1997): El orden político en las sociedades en cambio. Barcelona: Paidós.

IBARRA, H. (1992): «El laberinto del mestizaje». En AAVV: Identidades y sociedad. Quito: CELA-PUCE.
IngleHarT, R. (1984): "The Changing Structure of Political Cleavages in Western Society". En: Dalton, R., Flanagan, S. y Beck, P. (eds.): Electoral Change in Advanced Industrial Democracies: Realignment or Dealignment? Princeton: Princeton University Press

KowiI, A. (1997): Voces. Quito.

LipSET, S. M. y RokKan, S. (1967): Party, Systems and Voter Alignements. Free Press, New York, (Versión en castellano consultada: Lipset, S.M. y Rokkan, S. (1992): «Estructura de división, sistemas de partidos y alineamientos electorales» En Battle, A: Diez textos básicos de Ciencia Política. Barcelona: Airel)

MACAS, L. (1992): "El levantamiento visto por sus protagonistas". En AA.VV. Indios. Quito: Ildis, Abya Yala.

Mateos Díaz, A. y AlcÁntara SÁEz, M. (1998): Los diputados ecuatorianos: actitudes, valores y percepciones politicas. Quito: Programa de Apoyo al Sistema de Gobernabilidad Democrática-BID, CORDES, FLACSO, Universidad Andina Simón Bolívar y Maestría en Ciencia Política y Administración Pública, Pontificia Universidad Católica del Ecuador.

MORENO, S. (1992): El levantamiento indígena del Inti Raymi de 1990. Quito: FESO - Abya-Yala.

MonTERO, M. (1995): "Modos alternativos de acción política”. En: D’Adamo, O., García Beadoux, V., Montero, M. (Comps.): Psicología de la acción política. Buenos Aires: Paidós.

Panebianco, A. (1982): Modelos de Partido. Madrid: Alianza.

QUINTERO,R. y SYLVA, E. (1992): Ecuador: Una nación en ciernes. Quito: Flacso-Abya Yala.

RAMÓN, G. (1998): Los pueblos indígenas y negros del Ecuador. Sintesis Social, 3. Quito: SIISE.

Rosero, F. (1990): Levantamiento indígena: Tierra y precios. Quito: CEDIS.

SÁNCHEZ LÓPEZ, F. (1996): Organización, poder y desarrollo. Quito: P.U.C.E, Tesis de Licenciatura en Sociología y Ciencias Políticas.

SANCHEZ-PARGA, J. (1990): "La organización étnica impasses y periodizaciones". En: Sánchez-Parga J. (comp.): Etnia, poder y diferencia. Quito: Abya-Yala.

- (1989): Faccionalismo, organización y provecto étnico en los Andes. Quito: CAAP.

- (1986): La trama del Poder en la Comunidad Andina. Quito: CAAP.

SYLVA, P. (1990): La organización rural en el Ecuador: Autogestión, desarrollo y movimiento social. Quito: CEPP. Abya Yala.

SCHMiTTER, P. (1992): Teoría del Neocorporatismo. Guadalajara: Universidad de Guadalajara.

Tobar Donoso, J. (1992): El Indio en El Ecuador Independiente. Quito: EDIPUCE

YASHAR, D. (1998): "Contesting Citizenship: Indigenous Movements and Democracy in Latin America". Comparative Politics, vol. 31, 1, octubre. 


\section{RESUMEN}

El proceso de incorporación política de los sectores indígenas en el Ecuador. Pachakutik, un caso de estudio.

Las élites y el sistema político ecuatoriano han, tradicionalmente marginado, la integración y la participación en el proceso de toma de decisiones de los indígenas aunque este sector de la población formara parte de la etapa fundacional de la sociedad ecuatoriana. En las tres últimas décadas la situación se ha ido transformando y, paralelamente al proceso de democratización experimentado por el sistema político en su conjunto, los indígenas han comenzado a organizarse y se han ido convirtiendo en un actor con gran capacidad de presión en la vida política del país. Este trabajo reflexiona acerca del proceso de incorporación política de los indígenas en el marco institucional del Ecuador y, en particular, analiza el período que abarca desde la utilización de "modos alternativos de acción política" hasta su integración a las instituciones a partir del empleo de los instrumentos de "participación política" del sistema político. En este marco se analiza el papel desempeñado las organizaciones indígenas como la Confederación de Nacionalidades Indígenas del Ecuador (CONAIE) y por el Movimiento de Unidad Plurinacional Pachakutik-Nuevo País (MUPP-NP). La hipótesis principal de este trabajo es que el proceso de modernización rural llevado a cabo desde el Estado, la iglesia, las organizaciones no gubernamentales (ONG's) y los organismos internacionales ha facilitado la incorporación del sector indígena campesino al sistema político a través del desarrollo organizativo de las comunidades.

Palabras claves: Ecuador, indígenas, proceso de incorporación política, Pachakutik, CONAIE.

\section{ABSTRACT}

Elites and political system in Ecuador have traditionally marginalized integration and participation in process of decision-marking of indigenous people, even if this sector of population were part of the founders of ecuatorian society. During the last three decades, situation has changed because indigenous people start to be organized and has became in important actor with incidence in political life. This work focuses on process of political incorporation on indigenous people in institutional frame in Ecuador. Particularly, it analyzes the period of time from use of alternative methods of political action to integration in institutions with uses of instruments of political participation of political system. In this frame, rol devolopped by organizations as Confederacion de Nacionalidades Indígenas del Ecuador (CONAIE) y por el Movimiento de Unidad Plurinacional Pachakutik-Nuevo País (MUPPNP) are analyzed. Main hypothesis of this article is that process or rural modernization carried out by the State, the Catholican Church, NGO's and international organizations has facilitated the incorporation of rural indigenous sector into political system through community organizational development.

Key words: Ecuador, indigenous people, process of political incorporation, Pachakutik, CONAIE.

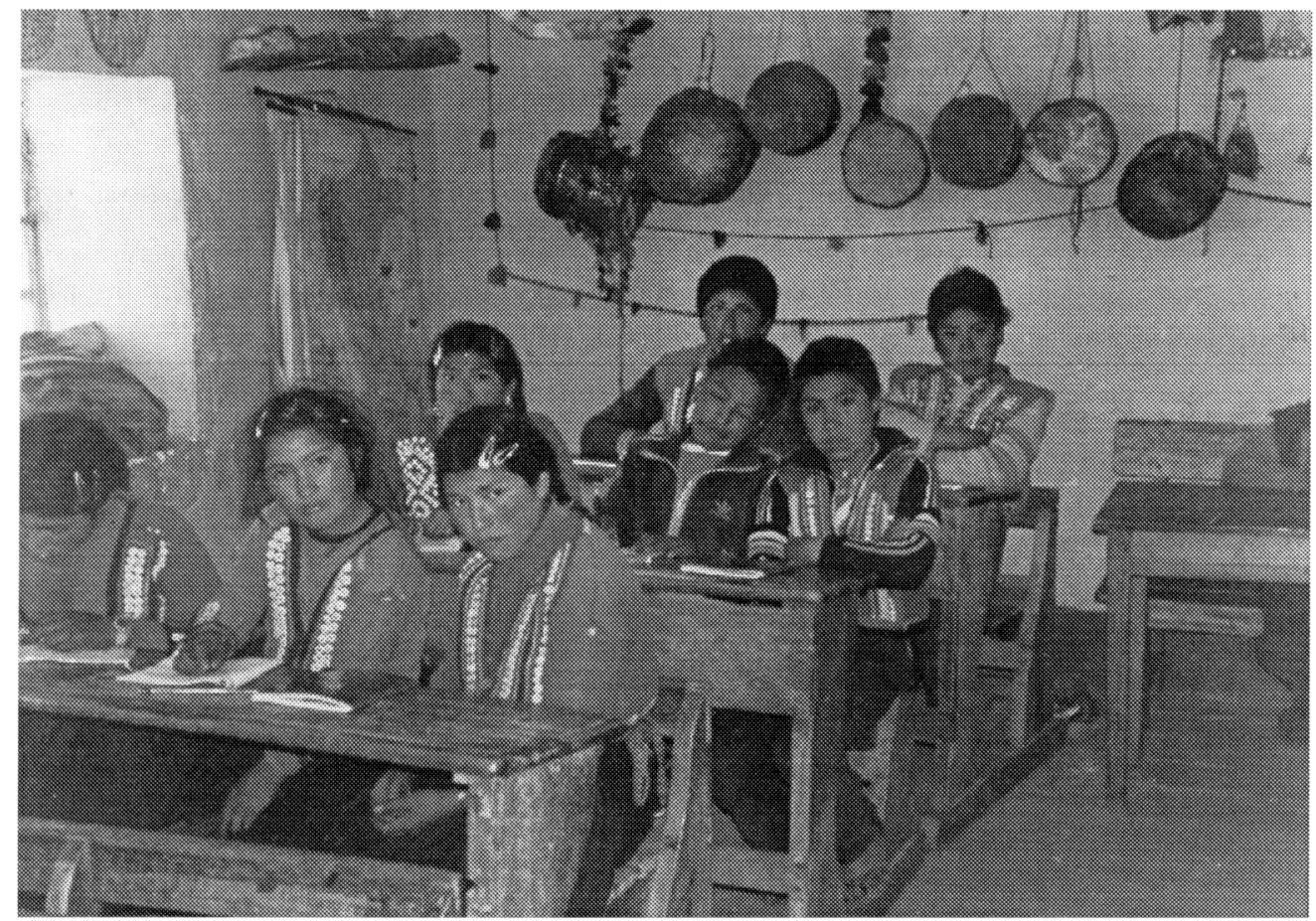

